\title{
Perceived barriers to the improvement of the performance transparency of hospitals in Iran: a qualitative study
}

\author{
HOSSEIN BOUZARJOMEHRI ${ }^{1, A, B, D-G}$, MOSTAFA SALARI-JAVAZM ${ }^{2, E, F}$, \\ ORCID ID: 0000-0001-8465-4383 \\ EBRAHIM JAAFARIPOOYAN ${ }^{1, A, D, E, ~}$, YASAMAN HERANDI ${ }^{3, B, D, E}$, ALI AKBARI-SARI ${ }^{1, A, D, E, ~ G ~}$ \\ ORCID ID: 0000-0001-7629-5018 ORCID ID: 0000-0003-2900-3240 ORCID ID: 0000-0002-6933-4071 \\ ${ }^{1}$ Department of Health Management and Economics, School of Public Health, Tehran University of Medical \\ Sciences, Tehran, Iran \\ ${ }^{2}$ Health Policy Research Center, Institute of Health, Shiraz University of Medical Sciences, Shiraz, Iran \\ ${ }^{3}$ Transparency for Iran Think-tank, Tehran, Iran
}

A - Study Design, B - Data Collection, C - Statistical Analysis, D - Data Interpretation, E - Manuscript Preparation, F - Literature Search, G - Funds Collection

Summary Background. Free access to information as a public right has become a critical issue in healthcare. Some health systems disclose information about hospitals' performance to influence patients' choices. However, there is little transparency in Iran.

Objectives. As a basic step to improve the transparency of hospitals' performance in Iran, this study was designed to explore the perceived barriers to transparency.

Material and methods. This qualitative study was conducted through eighteen face-to-face interviews with macro-, meso- and micro-level experts of the health system with different academic orientations. The data was analyzed using a thematic analysis method. Results. Five main themes were identified, including inadequate regular hospital performance data available to the government; lack of transparency culture among health system authorities; concerns about the transparency of hospitals' poor performance; absence of rule of law and immaturity of the country's health system governance, which weakens democracy. Therefore, the decision-making system mostly supports special groups rather than the public.

Conclusions. These barriers have become more prominent due to the existence of the conflict of interests among authorities and the power of pressure groups. Therefore, interviewees suggested that the necessary infrastructures be created prior to promoting transparency. Among the most important prerequisites is managing the conflict of interest in the health system to have decisions favor public interests.

Key words: public reporting of healthcare data, hospital administration, delivery of health care, health policy, access to information, Iran.

Bouzarjomehri H, Salari-Javazm M, Jaafaripooyan E, Herandi Y, Akbari-Sari A. Perceived barriers to the improvement of the performance transparency of hospitals in Iran: a qualitative study. Fam Med Prim Care Rev 2021; 23(2): 151-156, doi: https://doi.org/10.5114/ fmpcr.2021.105906.

\section{Background}

Information asymmetry is a considerable challenge in health systems that affects the rational choice of patients and makes them choose care services and providers without sufficient information [1]. Today, information and communications technologies have provided new tools for the authorities to improve information symmetry and increase the power of patients' choices in order to solve part of this lasting problem [2,3].

Transparency is defined as an "increased flow of timely and reliable economic, social and political information, which is accessible to all relevant stakeholders" [4]. This study focuses on the publishing of hospital performance information to the public in order to empower them to make informed choices. In a transparent health services market, people can compare different providers and choose the best one. In this way, in addition to increasing information symmetry between healthcare providers and people, the competition among providers rises. Although evidence showing the impact of public release of performance data on the quality and behavior of healthcare professionals or organizations is minimal $[5,6]$, many experts believe that not only can this transparency improve the quality of care, but it is also a basic human right [7-12].
Developed countries have taken steps along this path and have developed official websites to publish the performance information of their hospitals and physicians comparatively [13, 14]. Naturally, countries have developed transparency in their own ways due to the structure of their health system.

\section{Objectives}

Although studies have been conducted in developed countries, there are inadequate studies and actions in Iran. Therefore, as a basic step toward making Iran's health system transparent, this study aimed to explore the perceived barriers to improve the performance transparency of healthcare providers in Iran.

\section{Material and methods}

\section{Study design and participant selection}

A holistic, qualitative and in-depth study was designed to provide a general outline and overview of the subject. Eighteen participants were interviewed from different academic orientations and fields of expertise (Table 1) from public and private sector health providers, purchasers and consumer organiza- 


\begin{tabular}{|c|c|c|c|c|c|c|c|c|c|c|}
\hline \multirow[t]{2}{*}{ Characteristic } & \multicolumn{3}{|c|}{ Academic Degree } & \multicolumn{2}{|c|}{ Background } & \multicolumn{2}{|c|}{ Experiences (y) } & \multicolumn{3}{|l|}{ Level } \\
\hline & $\begin{array}{l}\text { A1: } \\
\text { MS }\end{array}$ & $\begin{array}{l}\text { A2: } \\
\text { MD }\end{array}$ & $\begin{array}{l}\text { A3: } \\
\text { PhD }\end{array}$ & $\begin{array}{l}\text { B1: } \\
\text { Clinical }\end{array}$ & $\begin{array}{l}\text { B2: } \\
\text { Non-C }\end{array}$ & \begin{tabular}{|l} 
E1: \\
5-15
\end{tabular} & $\begin{array}{l}\text { E2: } \\
15-30\end{array}$ & $\begin{array}{l}\text { L1: } \\
\text { Micro }\end{array}$ & \begin{tabular}{|l} 
L2: \\
Meso
\end{tabular} & $\begin{array}{l}\text { L3: } \\
\text { Macro }\end{array}$ \\
\hline \# & 6 & 4 & 8 & 8 & 10 & 11 & 7 & 5 & 6 & 7 \\
\hline
\end{tabular}

tions. Participants were selected from the micro (such as physicians and clinicians), meso (such as faculty members and hospital managers) and macro-levels (such as parliament, Ministry of Health (MoH) and Social Security Organization members) of the health system using a purposive quota method. The interviewees were graduates of medical sciences, public health, IT, technology policy and even law. Furthermore, some founders of websites crowdsourcing patient experiences were contacted and interviewed. In this way, efforts were made to see the barriers from the perspective of various individuals and stakeholders in order to create the necessary comprehensiveness. Some were known before the study, though most were found during the study. Data was analyzed at the same time as conducting the interviews, so the selection of interviewees continued until data saturation was achieved. Three interviewees dropped out of the study due to their busy schedule and lack of time for interviews and were replaced by other suitable experts.

\section{Data collection and settings}

The semi-structured face-to-face interview method was used, and the interview guide was organized into five sections, which included questions about technical, economic, institutional, cultural and political barriers, and was approved by two faculty members. The interviews were conducted solely by the first author. Some questions were directed toward specific interviewees, e.g. the barriers in law-making were directed to individuals related to the Islamic Consultative Assembly (Iranian Parliament). According to the participants, the interviews were conducted in their workroom. Before the interview, respondents were offered the necessary information through the information sheet. In addition, at the beginning of the interview, brief information was provided on the issue of the research and its method of conduct. The interviews were recorded, and field notes were made during the interview. After three days of interviewing, transcribing and coding began. The data was collected between January to August 2017. Each interview took about 40 to 70 minutes (average $50 \mathrm{~min}$ ).

\section{Data analysis and trustworthiness}

The collected data was analyzed by thematic analysis method. Two researchers performed data analysis and coding. Finally, the main themes were extracted, and two faculty members confirmed the whole process. After the initial coding and extraction of themes, in order to create more credibility, the preliminary results were reported at academic conferences and group discussions and were presented at some think tanks. Feedback from the audience, who were faculty members, thinkers and students, was a source of data for the correction and completion of the findings, as well as interpretation.

As a reflexivity declaration, two of the researchers were faculty members of healthcare administration, and the others were students of healthcare administration, medicine and pharmacy. The COREQ checklist was used to ensure the quality of the study report [15].

\section{Ethical considerations}

Ethical clearance was obtained from the authors' institute, and written informed consent was obtained from each interviewee. Confidentiality measures were taken, and only the researchers were aware of the interviewees' identity.

\section{Findings}

Five main themes were identified (Table 2).

Table 2. List of challenges to improve the transparency of hospitals in Iran

\begin{tabular}{|l|l|l|}
\hline No. & Theme & Subtheme \\
\hline 1. & Inadequate
\end{tabular}

\begin{tabular}{l|l|l|}
\hline 1. & Inadequate & - Fragmented existing health infor-
\end{tabular} hospital per- mation systems

formance data - Inaccuracy in available health data

available to the Failure to measure the output of government hospitals

- The means have turned to goals in the creation of health information systems

\begin{tabular}{ll|l}
\hline 2. & Concerns about & - Low quality of health services and
\end{tabular} the transpar- dilemmas of making it transparent ency of the poor - Health authorities' fear of their performance of performance transparency

hospitals $\quad$ - Adding to existing excessive bureaucracies in hospitals due to applying transparency and collecting data

\begin{tabular}{|c|c|c|}
\hline & & $\begin{array}{l}\text { cracies in hospitals due to applying } \\
\text { transparency and collecting data }\end{array}$ \\
\hline 3. & $\begin{array}{l}\text { Unsupportive } \\
\text { culture }\end{array}$ & $\begin{array}{l}\text { - The newness of the concept of } \\
\text { transparency in Iran's health gov- } \\
\text { ernance } \\
\text { - Lack of patient awareness of their } \\
\text { informational rights } \\
\text { - Physicians' disbelief of a patient's } \\
\text { informational rights }\end{array}$ \\
\hline 4. & $\begin{array}{l}\text { Weak rule of } \\
\text { law in the health } \\
\text { system }\end{array}$ & $\begin{array}{l}\text { - Past failures in enforcement of rules } \\
\text { in Iran's health system } \\
\text { - Inadequate laws for patient's rights } \\
\text { in the country } \\
\text { - Lobbying of powerful healthcare } \\
\text { providers against the transparency } \\
\text { of their performance }\end{array}$ \\
\hline 5. & $\begin{array}{l}\text { Immaturity of } \\
\text { the health gov- } \\
\text { ernance system }\end{array}$ & $\begin{array}{l}\text { - Managers' conservatism and their } \\
\text { fears of possible reactions and } \\
\text { resistance to transparency } \\
\text { - Lack of transparency at the higher } \\
\text { levels of the health system } \\
\text { - Conflict of interests at the highest } \\
\text { levels of health system decision- } \\
\text {-makers } \\
\text { - Decorative and perfunctory imple- } \\
\text { mentation of new plans, such as } \\
\text { transparency, in the health system }\end{array}$ \\
\hline
\end{tabular}

\section{Inadequate hospital performance data available to the} government

A major barrier is that the information which has to be published is not even available to the government. In fact, the performance of healthcare providers is not clear to the government either. The reason is that the $\mathrm{MoH}$ does not feel the need for this information, because it is satisfied with carrying out its primary duties. Although there are many health information systems at the moment, they are not integrated. One reason for the multiplicity of information systems is the lack of a goal in establishing health information systems. The purpose is lost, and the establishment of these systems has become the target, so these systems are set up at high costs; however, they are 
not used properly and have become decorative. For example, there should be a two-way information system, which means that after information is sent from the hospital to the $\mathrm{MoH}$, the hospital should receive a response to modify itself, but there is no such feedback and communications. As one of the interviewees pointed out, this fragmented health information system is rooted in fragmented health governance:

"There is such decentralized feudal governance at the $\mathrm{MoH}$, every faction independently collects information and makes its own rules" (a health policy faculty member and a former authority at the $\mathrm{MoH}$ ).

Because of the fragmented information system, the collected data and information will not be accurate. The statistics provided by the Ministry are varied, as there are many different statistics about simple information, such as the number of hospital beds. For example:

"A hospital declares the number of its employees more than the actual number to the budget department in order to receive more budget; however, at the time of recruitment, it declares the number of employees less than the actual number to the personnel department" (a health policy Ph.D. and a budget expert at the $\mathrm{MoH}$ ).

An interviewee believed that by enforcing transparency, authorities will offer false or misleading information, fraud will increase, and they will present their performance better than reality. He suggested that to prevent this, sufficient culture building and adequate data quality control must be created. In addition, transparency should be developed gradually from less susceptible data, so that its culture grows slowly. To prevent misrepresentation, another interviewee suggested public supervision by establishing a legal mechanism to report violations.

"Centralized monitoring can be corrupted, so we should go toward decentralized supervision. If hospital performance data is released to the public, they can monitor and report errors. Of course, there should be a good mechanism for whistleblowing and their protection" (a technology policy Ph.D. and head of a transparency initiative).

Another interviewee pointed out the barriers inherent in measuring hospitals' output. Hospitals are different and have different outputs. Therefore, we cannot easily measure and compare their outputs. We need to set the appropriate indicators for measurement and risk adjustment. Such scientific and technical capacities do not exist in Iran now. Besides, accreditation of hospitals is a growing program in Iran, which still has many deficiencies.

2. Concerns about the transparency of the poor performance of hospitals

According to some interviewees, the quality of hospital services is low, they said that hospital's quality improvement should be prior to the public report of hospital's performance. They believed if the quality of hospital services has not reached the desired level, transparency leads to fake and false information, and fraud increases. The quality of the performance should reach the level that the hospital itself feels the need to be transparent. Transparency is not desirable when a hospital has a lot of problems and low quality. On the contrary, the hospital is willing to be transparent if it has good quality. However, some other interviewees worried that the suspension of transparency for service quality improvement is an excuse for not implementing transparency. Furthermore, they believed that transparency would lead to quality improvement and without transparency, hospitals have little incentive to improve quality.

The fear of being punished through transparency was another barrier that one interviewee pointed out:

"Healthcare providers who have made some mistakes in the past or are currently abusing the lack of transparency to conceal their mistakes will resist transparency. If transparency is only accompanied by punishments, most physicians will oppose it, but if accompanied by incentives, too, then most accept it" (a physician).
Hospital managers and staff are concerned about new emerging tasks in addition to their current tasks. They believed that there is a lot of bureaucracy not allowing them to perform their main tasks, and transparency may increase these bureaucracies. They declared that currently there are many organizations, each one gathering information separately, and these repetitive processes would reduce the quality of services. A fragmented data collection process and the existence of multiple reporting systems should be merged. Therefore, they mentioned that it is necessary to eliminate old parallel bureaucracies along with the addition of new bureaucracies.

"Structures and bureaucracies should be reduced so that hospital managers can monitor performance and make the right decisions. Currently, hospital managers spend most of their time on redundant bureaucracies rather than improving quality. Transparency should not add to these bureaucracies, but should remove additional and repetitive ones; also adequate funding and resources in hospitals should be considered for the promotion of transparency. This is where hospitals welcome it. Otherwise, if a difficulty is to be added to the past difficulties, hospitals will resist" (a hospital manager).

Young doctors had their own concerns about transparency. As one pointed out, because of the low quality of medical education, young doctors acquire much of their knowledge during work experience, so their work will have lower quality compared to experienced doctors. Therefore, if their performance is published simultaneously with that of experienced physicians, it is oppressive to young doctors. While interested in being seen with transparency, young doctors are also concerned about comparing the quality of their performance with experienced doctors. The underlying cause of this issue is the poor quality of medical education that needs to be improved.

\section{Unsupportive culture}

The culture of transparency among the Iranian people is weak. Iranians are usually multi-layered and complex, and they do not easily reveal themselves. In addition to the culture of secrecy in Iranian society, there is a weak culture of transparency with Iranian authorities, especially health system authorities.

The idea of transparency of government has grown recently in the country, so naturally, its proper culture has not formed yet. According to the interviewees, in addition to the inadequate public culture of transparency, the culture of respect for a patient's informational rights is not appropriate either. In fact, information is not believed to be a patient right yet. For example:

"In a teaching hospital, patients should permit students to examine them, but this is not described to the patients, and patients are not aware of their rights. Even doctors do not know whether it is the patients' right or not. Therefore, neither patients demand such a simple thing nor doctors provide it".

In these cases, there are also no proper legal and institutional structures or functions for regulation. Furthermore, as one of the interviewees noted, even if people are aware of their rights to transparency, they do not have a civil society culture, and they do not claim their rights. Most people are not aware of their civil rights and how to pursue them, and they do not know why and how they can create an NGO or even do not believe that these actions may have results. Despite the government's slogan of supporting civil society, it does not actually empower civil societies and does not seem to have a deep belief in it.

\section{Weak rule of law in the health system}

Rule of law is more than legislation. It refers to a framework of rules and rights that everyone is accountable for, and the laws are applied equally to all. So legislation may exist but its implementation does not. The interviewees pointed out that in Iran's health system, the rule of law is weak, and this weakness prevents many efforts for the public interests. 
Transparency and access to information are among the rights of patients. Therefore, appropriate laws and regulations must be passed. Although, in the current situation with the weakness of the rule of law, passing a bill will not be effective enough. Lobbying of some powerful stakeholders in healthcare may postpone the process of healthcare transparency. Pressure groups can influence politicians, parliamentarians in particular. This situation will lead to the passing of laws in favor of interested groups rather than the public or cause the rejection of laws which benefit the public but endanger the interests of particular groups.

"When the rule of law is weak, authorities can put their opinions at priority and delay enforcement of the law" (a law M.Sc. and member of a transparency initiative).

In this situation, the view of the health authorities and their associates have a significant impact on the enforcement or non-enforcement of healthcare laws. Therefore, even if there is a transparency law, authorities can refuse to enforce it. With the power of personal opinion, lobbyists can influence the enforcement of transparency laws even at the executive level.

Lastly, the rules must have standards, like an executive guarantee. Non-standard laws put the rule of law at risk. These simple points are rarely considered in Iran's legislation. It happens very often that rules are not enforced due to their imperfection. For example, the Patients' Rights Charter has been provided for Iranian hospitals; however, there is no proper legal mechanism to enforce these rights, and it is unclear how these rights will be acquired and how the prosecution should occur If someone violates the rights. The patients' rights require specific laws, and the ways to acquire these rights, including informational rights, should also be considered in the law.

\section{Immaturity of the health governance system}

The interviewees believed that there is not yet sufficient maturation at the macro-level of health governance to understand innovations such as transparency, its benefits and its implementation methods. This maturation is not merely related to knowledge. There may be knowledge, but there is still no belief in it.

In addition, health system authorities are not accountable. Therefore, top-level health executives have become conservative for many reasons. In fact, they prefer to do nothing. It may be because of the authorities' fear of pressure groups. Pressure groups not only may have direct effects on the authorities, but they also have influences on the companions of authorities. For example, a minister even may start a vanguard project with the support of the president, and then the pressure groups can persuade the president to leave the minister alone! Therefore, authorities do not have the will to apply some extreme solutions, such as transparency, which may bring about resistance.

"In my opinion, the main reason for not solving the issues in our country is unwillingness rather than lack of ability. There is no will for enforcement; however, various other reasons are mentioned, like cultural excuses. If there is the will, culture can also be changed" (a health economics M.Sc. and an expert at a social security organization).

Some interviewees referred to the link between transparency and democracy. They implied that transparency has been developed in countries with a strong democracy. In countries where democracy is weak, the flow of information is also weak; so as Iran is moving toward democracy, it will apply transparency gradually.

"To move from dictatorship to democracy, you have to follow a path. After a dictatorship, democracy cannot be reached at once. From colonial dictatorship, we must move toward a benevolent dictatorship, then advisory dictatorship and ultimately participatory model" (a health policy faculty member and a former authority at the $\mathrm{MoH})$.

One of the barriers the interviewees pointed out was that there is no transparency at the highest levels of the health sys- tem or even other large institutions of the country. As a result, transparency at the lower levels would not take place. As long as the decision-making process of the health system is not transparent, transparency of healthcare providers will not be developed at all or not be desirable enough, because formal and informal interactions and relationships and their impact on decisions are not transparent, and decisions are not made for the benefit of the public. Inadequate transparency at macro-levels allows for the negative effects of pressure groups and conflicts of interest and thus can undermine the transparency of micro-levels. Another interviewee said:

"To find the starting point for developing transparency, we should refer to the words of Imam Ali (PBUH), who said: "People are more similar to their governors than their parents". When the superior levels are transparent and responsive, one can expect lower levels to be transparent and accountable" (a hospital manager).

In addition, another interviewee stated:

"Physicians and hospital staff will resist transparency and ask if other parts of the country have become transparent" (a physician).

However, transparency certainly should start from a point, and it can be argued that the priority is where transparency affects the lives of people.

Some interviewees believed that the most important barrier is the conflict of interest. An interviewee, who was a physician with a background of management at the highest levels of the health system, stated that:

"Authorities who have to make policies are physicians, heads or shareholders of public and private hospitals. Transparency will not be developed until the conflict of interest is resolved" (a physician and a former high-level authority at the $\mathrm{MoH}$ ).

As health policymakers are working at hospitals as physicians and managers, they apply policies that benefit hospitals most. So improving the transparency of healthcare performance may not be a priority. In addition, their participation in the private sector makes this barrier even more complicated. The government cannot stand against private sector healthcare providers, because the government officials are also in the private sector. The structure of the health system of the country is such that the private sector rides on the public sector.

In this case, some interviewees believed that applying conflict of interest policies in Iran's health system should be prior to any kind of health system modification, even transparency. They implied that if conflict of interest is not managed and the culture of a proper attitude of service providers towards people and patients is not formed, then forcing the executives to develop transparency might end up with the creation of decorative websites which do not provide useful information in practice. We can say that the same thing has also happened to the Electronic Health Record (EHR) in Iran at present.

\section{Discussion}

The findings show that there are important barriers in developing the transparency of hospitals, many of which are rooted in other deep issues about Iran's health governance. The above-mentioned barriers were presented from minor to major. Although there are technical and cultural barriers, the findings show that political barriers are more important. Some of the barriers are only within the health system, and some are from the whole governance system. For example, barriers such as the weak rule of law and the immaturity of health governance are mainly related to the whole government of Iran; however, they may be more severe in the health system. One can argue that the cultural barriers are deeper and rooted in social manners which have been created over the decades. Although this is true, the interviewees believed that if the political system works efficiently, culture can be modified. Prior to implementing any 
plan for transparency, these barriers and relative solutions must be considered. Many of barriers may be completely solved by an appropriate, acceptable and applicable plan. However, some of them will not be solved totally. Therefore, any progression and development should not be postponed for perfect conditions.

The findings are comparable with other studies. For example, the gap in the quality of health services has been discussed in other studies, so increasing transparency in a situation where the quality of service is not ideal can be challenging [16-18]. In the area of legal barriers, as the evaluation of the Iranian Parliament Research Center showed, about 70 percent of the fifth development plan (the last Iranian Development Plan at the time of this study) has not met the standards of lawmaking, and most of the plans were not implemented as prescribed by the law [19]. This evaluation also confirms the existence of barriers related to the weak rule of law.

Other studies about cultural barriers also confirm the lack of a culture of transparency in Iran. For example, Ferasatkhah [20], in his book, introduces the culture of not being transparent as one of the most important characteristics of the Iranians. Some evidence related to Iranian culture calls it hypocrisy and dishonesty. However, this may be exaggerated. For example, Elaine Sciolino says, "Its people are warm and welcoming but do not reveal themselves readily. Conversation is full of politeness, self-abnegation, hypocrisy and lying, all to avoid offense and loss of face..." [21]. These characteristics may prevent the transparency of healthcare performance. It is not clear, however, if this attribute in Iranians is more or less than in other nations. Therefore, this may be a common human attribute.

Currently, most studies about the barriers of implementation of information technologies which develop transparency in healthcare in Iran's health system are claiming that technical and funding barriers are the most important barriers [e.g. 22$-24]$. However, the findings of the current study show that the most important barriers in this field are political issues, pressure groups, conflicts of interests and power relations in Iran's health system, and these political barriers do not allow other technical and operational issues to be solved. As one of the interviewees noted, transparency policy requires prerequisites and policy capacities, including reforming the decision-making and policy-making system at the level of health system governance. These differences in the findings may be rooted in the different methods of study. Those studies used a basic quantitative approach, which does not focus on the key informants and deep interviews and may result in misinterpretation.

Although some perceived barriers to improve the performance transparency of hospitals are unique to Iran's health system, many of them also exist in other countries. For example, Tim Kelsey, who launched the NHS Choices website, and his colleagues reported barriers such as "the lack of sufficient and standard data on a regular basis for all types of care" and "political controversies against transparency" [10]. They also suggested important solutions to deal with these barriers, e.g. political courage and the existence of real and strong support from the elite and the superior authorities of the health system for transparency, participation, cooperation and support of all stakeholders, in particular, health service providers, in the planning and implementation of the transparency program, as well as developing the program gradually, step by step, and starting it with existing data (start transparency with inadequate data; do not wait for perfect data) [10].
A similar study conducted in Australia examined the barriers of effective public reporting of hospital performance and the progression of transparency after its implementation. This study shows that barriers like unclear objective/purpose or target audience, complexities of data \& data collection, lack of appropriate data translation, providers' institutional cultures resistant to public reporting, poor consumer health literacy and lack of consumer empowerment or consumerist culture may affect the progression of transparency and its advantages [25]. Some similar barriers have been observed in the United States and Uruguay $[11,26,27]$.

Although this study only examined the barriers, there are opportunities to promote transparency which can be studied in the same way. Probable opportunities may be the emergence of public awareness about civil rights and the development of mass media and social media networks. In addition, there are growing numbers of think thanks and social activists who support the notion of transparency and start initiatives. Despite the existence of major barriers in developing transparency in Iran's hospitals, transparency of hospitals is not impossible. If there is the will and there is support from the public, elites and authorities, identified barriers can be solved gradually by planning and conducting specialized studies.

\section{Limitations of the study}

Among the research limitations were difficulties of access to authorities and scholars for interviews. If one interviewee was not accessible, another suitable person was found. For example, high-level officials of the health system were not accessible. However, attempts have been made to use the same former high-level officials who were accessible and responsible.

\section{Conclusions}

There are important barriers to improve the transparency of the hospitals in Iran, including inadequate standard and accurate information, lack of transparency culture among people and authorities, fear and concern about transparency (especially due to poor service quality), weak rule of law and immaturity in health governance. However, the most important barrier, which the interviewees referred to, was "authorities' unwillingness to develop transparency". This barrier has become more prominent due to the existence of the conflict of interest among authorities and the power of pressure groups to influence the public sector. Therefore, the interviewees suggested that the necessary infrastructures should be created prior to developing transparency. One of the most important infrastructures is modifying the health governance system and managing conflict of interest in the healthcare system of the country.

Acknowledgments. This article is derived from a Master's Thesis entitled Challenges and Solutions for Promoting Transparency in Iranian Hospitals, under code number 9311382003, at Tehran University of Medical Sciences. In addition, the Hekmat Institute for Policy Research and Strategic Studies and Transparency for Iran think tank have supported this study. Accordingly, Dr. Mahdi Sanaei and Dr. Mahdi Mokhtari Payam are gratefully acknowledged for their support, encouragement and cooperation. We would also like to thank the participating informants for their time and valuable insights.

Source of funding: This article is derived from a Master's Thesis entitled Challenges and Solutions for Promoting Transparency in Iranian Hospitals, under code number 9311382003, at Tehran University of Medical Sciences. In addition, the Hekmat Institute for Policy Research and Strategic Studies and Transparency for Iran think tank have supported this study.

Conflicts of interest: The authors declare no conflicts of interest. 


\section{References}

1. Folland S, Goodman AC, Stano M. The economics of health and health care. Ghazanfari S, Kazemi A, Nik-Afshar M, et al. translation. 7th ed. Tehran: Sobhan Publication; 2013: 233-252 (In Persian).

2. O'Reilly T. Gov 2.0: The promise of innovation: Forbes. 2009 [cited 09.06.2018]. Available from URL: https://www.forbes. com/2009/08/10/government-internet-software-technology-breakthroughs-oreilly.html\#6dbada893b7b.

3. Lathrop D, Ruma L. Open government: collaboration, transparency, and participation in practice. Newton (MA): O'Reilly Media, Inc.; 2010.

4. Bellver A, Kaufmann D. Transparenting transparency: initial empirics and policy applications. World Bank Policy Research Working Paper, 2005. [cited 03.05.2020]. Available from URL: https://dx.doi.org/10.2139/ssrn.808664.

5. Ketelaar NA, Faber MJ, Flottorp S, et al. Public release of performance data in changing the behaviour of healthcare consumers, professionals or organisations. Cochrane Database Syst Rev 2011; 11: CD004538, doi: 10.1002/14651858.CD004538.

6. Metcalfe D, Rios Diaz AJ, Olufajo OA, et al. Impact of public release of performance data on the behaviour of healthcare consumers and providers. Cochrane Database Syst Rev 2018; 9: Cd004538, doi: 10.1002/14651858.CD004538.

7. Fung $\mathrm{CH}$, Lim Y-W, Mattke S, et al. Systematic review: the evidence that publishing patient care performance data improves quality of care the impact of publishing performance data on quality of care. Ann Intern Med 2008; 148(2): 111-123.

8. Aligning forces for quality. Can measuring physician performance improve health care quality? 2011 [cited 09.06.2018]. Available from URL: https://goo.gl/dfFhML.

9. Cooper Z, Gibbons S, Jones S, et al. Does hospital competition save lives? Evidence from the English NHS patient choice reforms. Econ $J$ (London) 2011; 121(554): F228-F260.

10. Henke N, Kelsey T, Whately H. Transparency - the most powerful driver of health care improvement? McKinsey's Health Systems and Services Practice, 2011 [cited 13.10.2017]. Available from URL: https://goo.gl/5LXq4q.

11. Sinaiko AD, Rosenthal MB. Increased price transparency in health care - challenges and potential effects. N Engl J Med 2011; 364(10): 891-894.

12. Bridgewater B, Irvine D, Keogh B. NHS transparency. BMJ 2013; 347, doi: 10.1136/bmj.f4402.

13. Rechel $B$, McKee $M$, Haas $M$, et al. Public reporting on quality, waiting times and patient experience in 11 high-income countries. Health Policy 2016; 120(4): 377-383.

14. Cacace M, Ettelt S, Brereton L. How health systems make available information on service providers: experience in seven countries. Rand Health Q 2011; 1(1): 11.

15. Tong A, Sainsbury P, Craig J. Consolidated criteria for reporting qualitative research (COREQ): a 32-item checklist for interviews and focus groups. Int J Qual Health Care 2007; 19(6): 349-357.

16. Vatankhah S, Hosseini AF. Services quality analysis using importance-performance analysis (IPA) tool in selected general hospitals in Tehran: 2011. SJSPH 2013; 11(1): 59-70.

17. Izadi A, Jahani Y, Rafiei S, et al. Evaluating health service quality: using importance performance analysis. Int J Health Care Qual Assur 2017; 30(7): 656-663.

18. Gorji HA, Royani S, Mohseni M, et al. Primary health care quality in Iran: a systematic review and meta-analysis. Fam Med Prim Care Rev 2019; 21(1): 71-77.

19. Parhizkari S-A, Rezghi A, Rohani S-A. About Iran sixth development plan (13) - Reviewing some of the principles of lawmaking in the fifth development plan law. Islamic Republic of Iran Parliament's Research Center, 2015 [cited 09.06.2018]. Available from URL: http:// rc.majlis.ir/fa/report/show/951136.

20. Ferasatkhah M. We Iranians: a historical and social contextualizing of Iranian ethos. 2nd ed. Tehran: Ney Publication; 2015.

21. Sciolino E. Persian mirrors: the elusive face of Iran. New York: Simon and Schuster; 2001.

22. Jahanbakhsh M, Tavakoli N, Mokhtari H. Challenges of EHR implementation and related guidelines in Isfahan. Procedia Computer Science 2011; 3: 1199-1204.

23. Sharifi M, Ayat $M$, Jahanbakhsh $M$, et al. E-health implementation challenges in Iranian medical centers: a qualitative study in Iran. Telemed J E Health 2013; 19(2): 122-128.

24. Meidani Z, Sadoughi F, Maleki MR, et al. Organization's quality maturity as a vehicle for EHR success. J Med Syst 2012; 36(3): 1229-1234.

25. Canaway R, Bismark M, Dunt D, et al. Perceived barriers to effective implementation of public reporting of hospital performance data in Australia: a qualitative study. BMC Health Serv Res 2017; 17(1): 391, doi: 10.1186/s12913-017-2336-7.

26. Sinaiko AD. How do quality information and cost affect patient choice of provider in a tiered network setting? Results from a survey. Health Serv Res 2011; 46(2): 437-456.

27. Carranza D. OGP Awards First Place Speech: open government partnership. 2015 [cited 03.05.2020]. Available from URL: https://www. youtube.com/watch?v=VtDDTvG_8Z0. Archived at: http://www.aparat.com/v/5uFMy.

Tables: 2

Figures: 0

References: 27

Received: 28.03.2020

Reviewed: 9.04.2020

Accepted: 15.05 .2020

Address for correspondence:

Prof. Ali Akbari-Sari

Department of Health Management and Economics

School of Public Health

Tehran University of Medical Sciences

Poursina St, 16 Azar St, Keshavarz Boulevard

Tehran

Iran

Tel.: +98912725 1294

E-mail: akbarisari@tums.ac.ir 